\title{
Mechanical properties of plain-woven CFRP reinforced by spread fiber tow during and after drop-weight impact
}

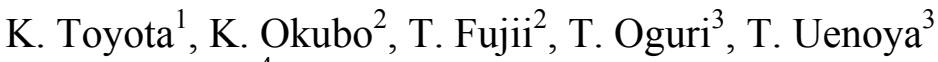 \\ \& T. Sugawara ${ }^{4}$ \\ ${ }^{1}$ Doshisha University, Japan \\ ${ }^{2}$ Department of Mechanical Engineering and Systems, \\ Doshisha University, Japan \\ ${ }^{3}$ Technology Research Institute of Osaka Prefecture, Japan \\ ${ }^{4}$ Maruhachi Company Limited, Japan
}

\begin{abstract}
For this paper, the impact behaviors and the damage state of plain-woven CFRP reinforced by spread tow due to falling weight were evaluated. Stress-Strain responses of the CFRP using spread tows were investigated under drop-weight impact loading at room temperature. Three leveled impact energy was applied to the surface of the specimen in the drop-weight test. The peak load and absorbed energy were then compared with those of a conventional one and the experimental results showed that the peak load and absorbed energy of the developed CFRP were higher. A large amount of energy was absorbed due to the propagation of macro cracks and delaminations near the counter surface in the developed CFRP. When reinforced by spread tow its structure absorbs a large amount of energy after the initial stage of impact damage. The SAI (static strength after impact) and the FAI (fatigue life after impact) were also examined and the tensile test results showed that the static strength retention of the developed CFRP was higher than those of a conventional one. The developed CFRP also has long fatigue life under the tension-tension cyclic load after the impact. It was found that it maintained superior mechanical properties compared to the original, even after the material was damaged due to impact, because critical propagation of the debonding was prevented around the warp of thin cloth. This paper concludes that reinforcing with spread tow is effective for improving the mechanical properties of plain-woven CFRP during and after impact loading.
\end{abstract}

Keywords: impact, plain-woven fabric, CFRP, spread tows, energy absorption. 


\section{Introduction}

Woven fabric composites have gained relatively widespread application due to a number of advantages. Woven fabric composites provide more balanced properties, enhance impact resistance and improve ease of handling [1]. However, they have flexure of tow at the crossover point between the tows. The stress concentration occurs at the cross over points. Therefore, woven fabric composites exhibit complex mechanical response and damage behavior under applied loading. The mechanical properties of composite such as tensile strength and stiffness degrade as compared with cross-ply composites [2, 3].

Kawabe has developed a method in which tow can be efficiently spread [4]. By using this method, we prepared wide $(15 \sim 20 \mathrm{~mm})$ and thin $(0.05 \sim 0.1 \mathrm{~mm})$ tows. We call this tow 'spread tow'. Furthermore, a new weaving technique of woven fabric using spread fiber tows was developed. The advantages of spread tow are (1) to develop mechanical properties of composites because of diminishing flexure of tow, (2) to penetrate easily high viscosity resin, such as thermoplastic resin, into thin plain-woven fabric and (3) to cut cost to use 'large tow' which consists of large number of carbon fibers (about 48,000 320,000). We have already confirmed that static and fatigue properties of composites using spread tows improved. Furthermore, we also revealed that crack was constrained by using spread tows for composites.

Advanced Composite Materials are widely used for the structural component due to their excellent mechanical properties such as high specific strength and stiffness. However, mechanical or structural components made of composite materials may suffer large damage extension when subject to impact loads, with the corresponding decrease of their residual strength and the subsequent risk of structural failure under service loads. There are many issues that determine the response of the composite materials to impact loads [5-10]. It hoped that the excellent properties of composites using spread tow make a contribution to improve the property of impact, however, it was not recognized.

This paper discusses mechanical properties of newly-developed plain-woven CFRP using spread tow during and after drop-weight impact. Absorbed energy was measured for new plain-woven CFRP and conventional one during dropweight impact. Static and fatigue properties after impact were examined. We focus on the effect of difference in structure on internal damage formation and propagation.

\section{Experimental procedure}

\subsection{Materials and specimens}

Figure 1 shows plain-woven fabric using spread tows. In this study, 4 types of plain-woven fabric were used as reinforcement. Table 1 lists type of specimen. We call plain-woven CFRP using spread tows SF12K and SF24K respectively. Plain-woven CFRP using $3 \mathrm{~K}$ tows and $6 \mathrm{~K}$ tows are called PW3K and PW6K respectively. Prepreg-sheet used relatively high viscosity resin (Maruhachi Co., Ltd.) was used for SF12K-CFRP. 


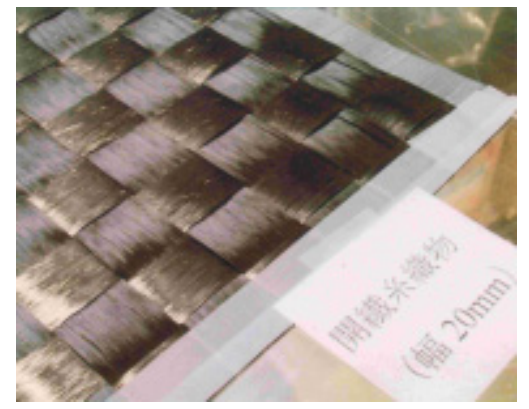

Figure 1: $\quad$ Photograph of plain-woven fabric using spread tows.

Table 1: $\quad$ Type of specimen.

\begin{tabular}{ccccc}
\hline & $\begin{array}{c}\text { SF-12K } \\
\text { (New) }\end{array}$ & $\begin{array}{c}\text { SF-24K } \\
\text { (New) }\end{array}$ & $\begin{array}{c}\text { PW-3K } \\
\text { (Conventional) }\end{array}$ & $\begin{array}{c}\text { PW-6K } \\
\text { (Conventional) }\end{array}$ \\
\hline \hline Number of fibers in tow & 12,000 & 24,000 & 3,000 & 6,000 \\
\hline Number of ply & 23 & 11 & 9 & 6 \\
\hline Fiber volume fraction & $50.4[\%]$ & $50.4[\%]$ & $50.4[\%]$ & $50.4[\%]$ \\
\hline Thickness of specimen & $2[\mathrm{~mm}]$ & $2[\mathrm{~mm}]$ & $2[\mathrm{~mm}]$ & $2[\mathrm{~mm}]$ \\
\hline
\end{tabular}

\subsection{Experiments}

\subsubsection{Punching test}

All tests were conducted under the laboratory condition $\left(23 \pm 2^{\circ} \mathrm{C}, 60 \pm 5 \% \mathrm{RH}\right)$. Punching tests were conducted with a SHIMADZU Co. HTM-10kN. The punching velocity was $4.4 \mathrm{~m} / \mathrm{s}$. The impactor has a hemispherical tup with a diameter $12.7 \mathrm{~mm}(1 / 2$ in). The specimen was clamped between two steel plates with cut-out hole of $25.4 \mathrm{~mm}$ ( 1 in) in diameter.

\subsubsection{Drop-weight impact test}

Impact tests were conducted with an instrumented drop-weight impact testing system referred to Japanese Industrial Standards (JIS K 7085). The impactor mass was $4.10 \mathrm{~kg}$. The incident kinetic energy was 2,4 and $6 \mathrm{~J}$ varying height of impactor. To prevent a second impact, the impactor was caught on the rebound.

\subsubsection{Tensile test after impact}

Parallel-sided specimens of 30mm width and 190mm length were cut out of each laminate. Figure 2 shows geometry and dimensions of specimen. Drop-weight impact tests were conducted before tensile test. The impact energy was $4 \mathrm{~J}$. Tensile tests were conducted at a cross-head speed of $0.5 \mathrm{~mm} / \mathrm{min}$ with a universal testing machine (SHIMADZU Co. AUTOGRAPH). 


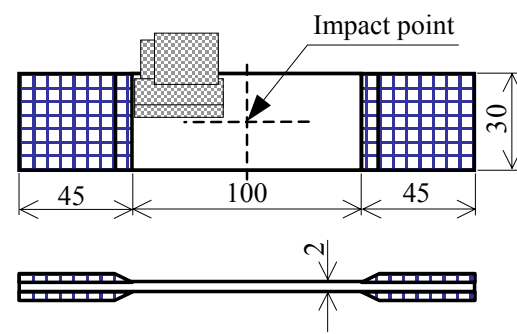

Figure 2: Geometry of specimen.

\subsubsection{Tension-tension fatigue test after impact}

A servo-controlled hydraulic testing machine (SHIMADZU Co. SERVOPULSER-50kN) was used for the fatigue tests. In fatigue tests, the specimen was subjected to cyclic loads having a sinusoidal wave at a frequency of $5 \mathrm{~Hz}$ and a stress ratio of 0.1 .

\section{Results and discussions}

\subsection{Reaction force-displacement curves due to falling weight}

Figure 3 shows the typical reaction force - displacement curves during punching test for the PW6K and SF24K. Impacts on both specimens produced the characteristic response of an initial rise in load to a load $\mathrm{P}_{\mathrm{k}}$, followed by sudden drop, and a continuing rise to a peak and a final decline to zero load. We call $\mathrm{P}_{\mathrm{k}}$ initial damage load. When the tup penetrates, $\mathrm{P}_{\max }$ observed. The experimental results showed that the $\mathrm{P}_{\mathrm{k}}$ and $\mathrm{P}_{\max }$ of the developed CFRP were higher than those of conventional one.

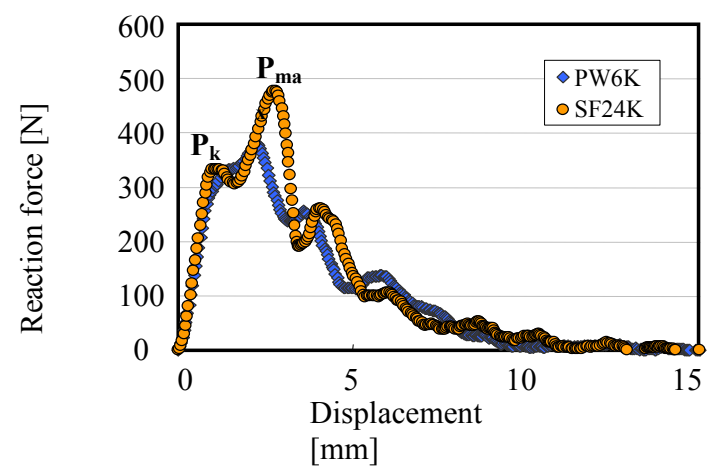

Figure 3: Reaction force-displacement curves due to falling weight. 


\subsection{Absorbed energy from initial knee to peak load}

Figure 4 shows the absorbed energy of PW6K, SF24K and SF12K until $\mathrm{P}_{\max }$. The experimental results showed that the absorbed energy of SF24K and SF12K were higher than that of conventional one. Difference of the absorbed energy in SF24K and SF12K was caused toughness of resin [11]. The value of fracture toughness of resin used for SF12K is higher than that of SF24K and PW6K. Figure 5 shows the absorbed energy of PW6K, SF24K and SF12K from initial knee to $\mathrm{P}_{\max }$. Large amount of energy was absorbed for the SF-CFRP, compared with PW-CFRP. It was found that the developed CFRP reinforced by spread tow has advantage in its structure that absorbs large amount of energy after damaged in the initial stages.

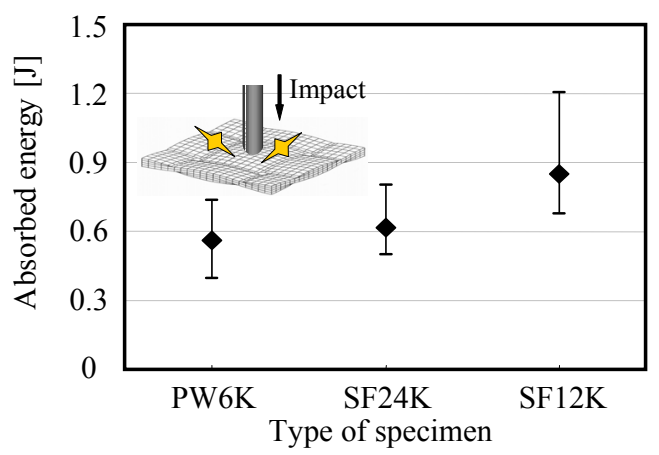

Figure 4: $\quad$ Absorbed energy until peak load.

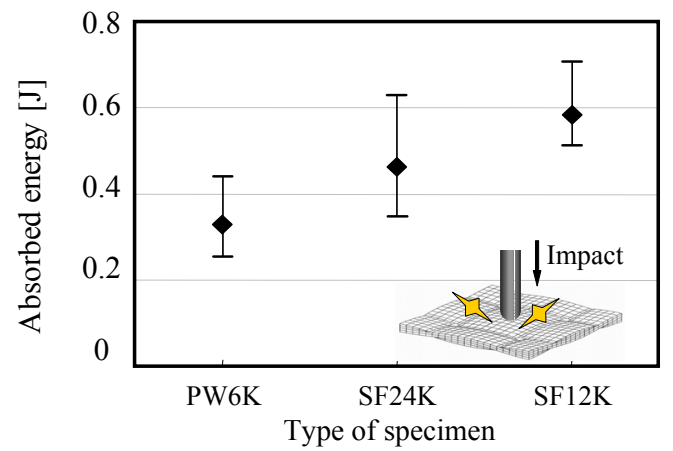

Figure 5: Absorbed energy from initial knee to peak load.

\subsection{Internal damage state after impact}

Figure 6 shows photographs of internal damage state for PW6K and SF24K that were subjected to drop-weight impact loading (impact energy of $4 \mathrm{~J}$ and $6 \mathrm{~J}$ ). Figure 6 (a) shows internal damage state for PW6K and SF24K after impact by 
drop weight (100mm high). It was observed that a lot of transverse cracks, local delamination and fiber breaking at near counter surface for both PW6K and SF24K. These internal damages for PW6K were observed at the impact surface and internal area while those for SF24K were observed only near the counter surface. Furthermore, local delamination at near counter surface for SF24K was large, compared with that for PW6K.

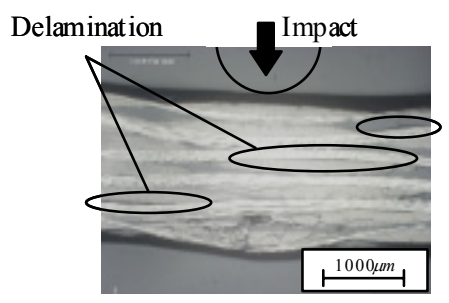

PW6K

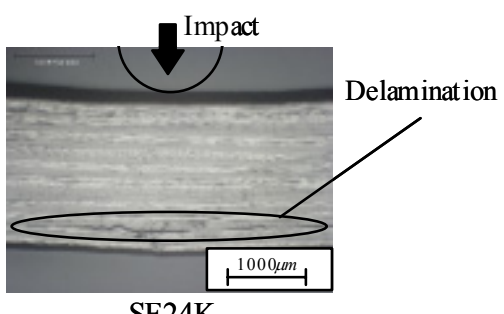

SF24K

(a) $4 \mathrm{~J}$ (100mm high)

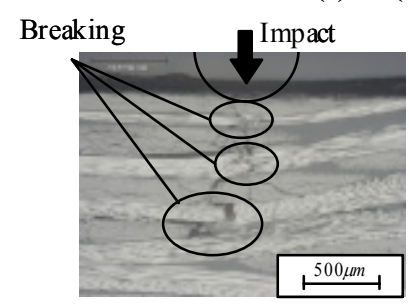

PW6K

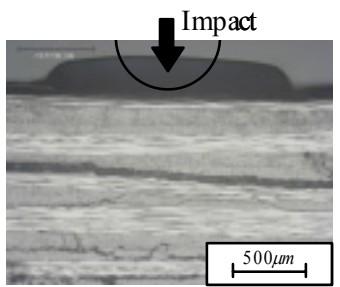

$\mathrm{SF} 24 \mathrm{~K}$

(b) $6 \mathrm{~J}$ (150mm high)

Figure 6: Internal damage state of PW and SF after impact by falling weight.

\subsection{Evaluation of the delamination observed by ultrasonic C-scanner}

An image of the damage extension was observed by ultrasonic C-scanner (Hitachi Scanning Acoustic Microscope 210) of each impact-damaged specimen. Figures 7 and 8 show the C-Scan images of delamination for PW3K and SF12K respectively at different impact energy.

The shape of overall delamination area of both specimens increases as impact energy increase. The delamination for SF12K specimen was significantly propagated at low impact energy (2J), which observed from counter surface. It was found that large amount of energy was absorbed due to the propagation of macro cracks and delaminations near the counter surface in the developed CFRP.

\subsection{Effect of spread tow on the static properties after impact}

Figure 9 shows the typical stress-strain curves under static loading for the PW3K and SF $12 \mathrm{~K}$ that were impact damaged (the impact energy was 4J). Figure 10 also 
shows the normalized tensile strength after impact. It was found that the static strength retention of the developed CFRP was higher than those of conventional one.

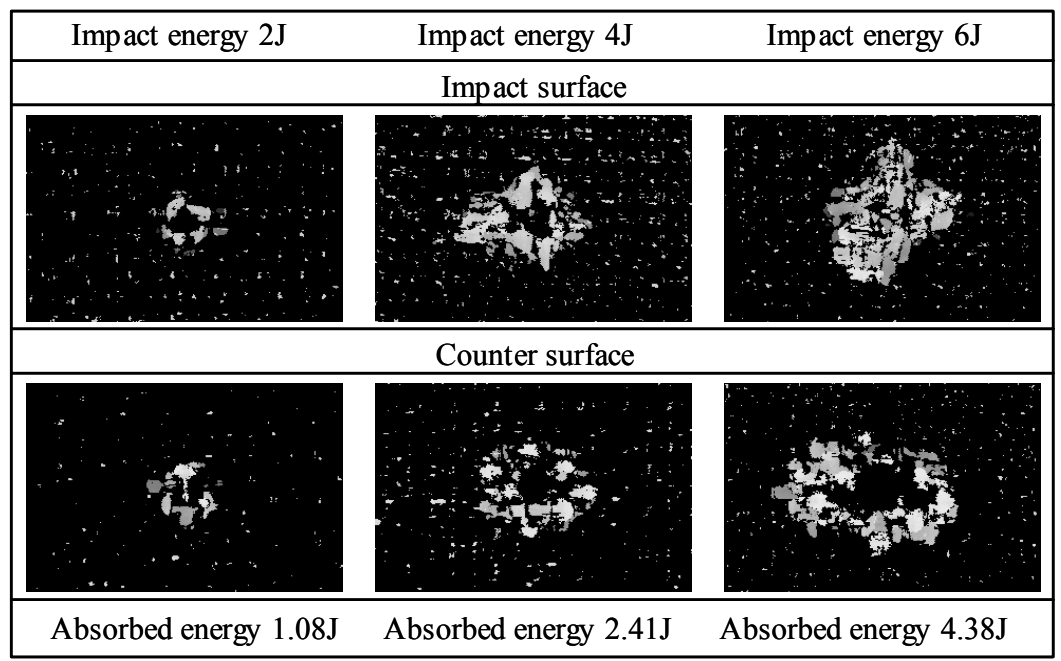

Figure 7: Delamination of PW3K observed by ultrasonic C-scanner at each impact energy.

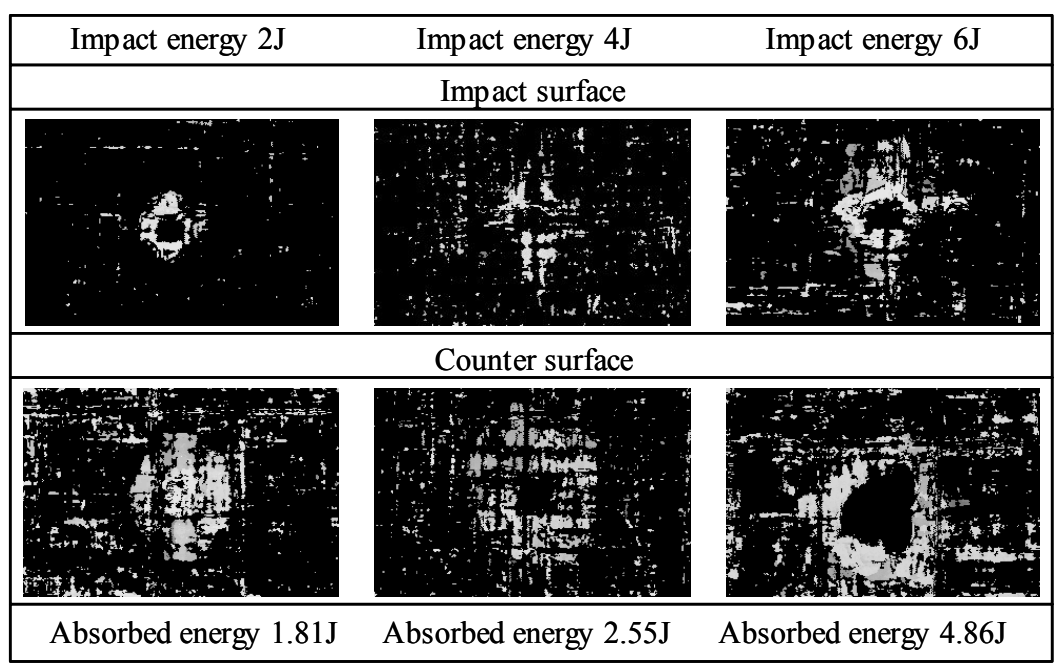

Figure 8: Delamination of SF12K observed by ultrasonic C-scanner at each impact energy. 


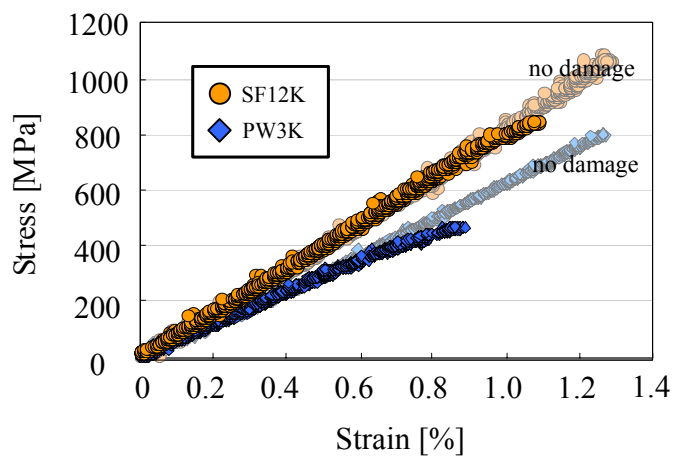

Figure 9: $\quad$ Stress-strain curve.

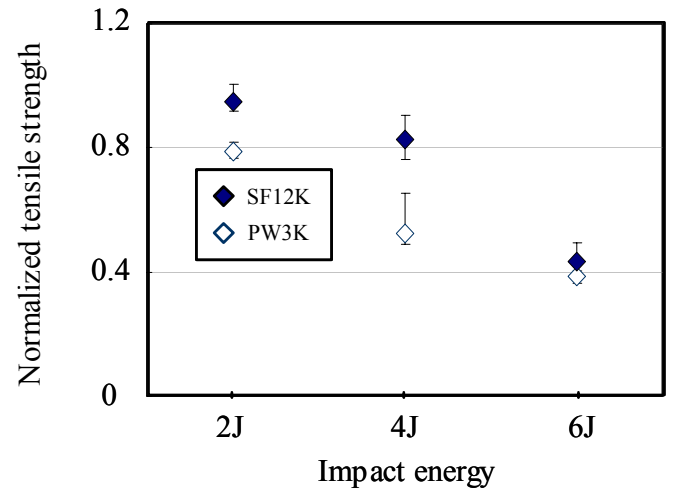

Figure 10: Normalized tensile strength after impact.

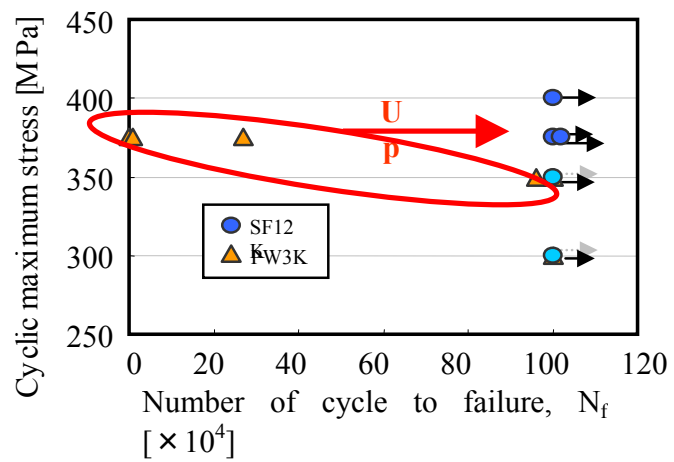

Figure 11: S-N diagrams.

\subsection{Effect of spread tow on the fatigue properties after impact}

Figure 11 shows the S-N diagrams obtained in fatigue tests. The fatigue life of SF12K was longer than that of PW3K. This results show that the fatigue life of 
the developed CFRP is longer than that of conventional one even after the material was damaged due to impact.

Figure 12 shows the C-Scan images of delamination for PW3K and SF12K, which were sustained $10^{6}$ cyclic loads. Significant propagation of delamination was observed for PW3K while few propagation of delamination was found in the $\mathrm{C}-\mathrm{Scan}$ image of SF12K. These results indicate that if the developed CFRP subject to impact load, the thin cloth of developed CFRP prevents fiber breaking. The impact damages of conventional CFRP were concentrated in the point of impact. However, those of developed CFRP were dispersed. It was found that the developed CFRP maintained superior mechanical properties close to original them, even after the material was damaged due to impact, because critical propagation of the damage was prevented around the warp of thin cloth.

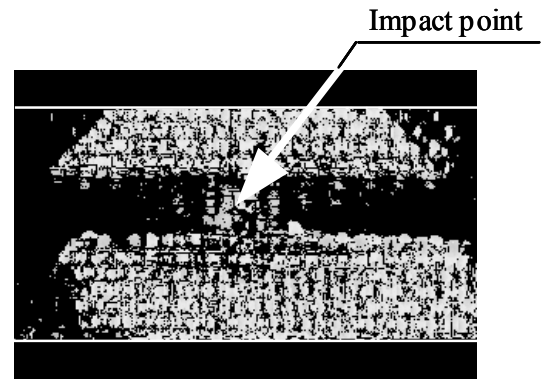

PW3K $\sigma_{\text {max }}=350 \mathrm{MPa} 2 \times 10^{6}$ cycles

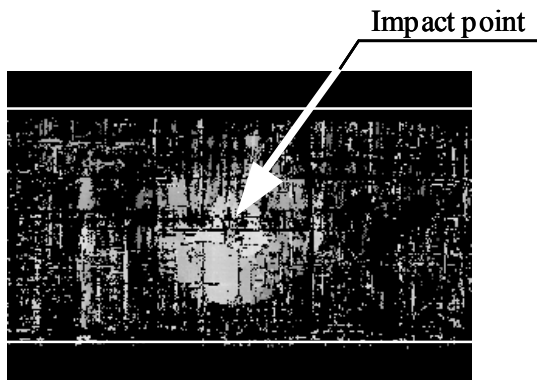

$\mathrm{SF} 12 \mathrm{~K} \quad \sigma_{\max }=400 \mathrm{MPa} 2 \times 10^{6}$ cycles

Figure 12: Delamination after FAI obtained by ultrasonic C-scanner.

\section{Conclusion}

In this study, impact behaviors and damage state of plain-woven CFRP reinforced by spread tow due to falling weight was evaluated. The SAI (static strength after impact) and the FAI (fatigue life after impact) were also examined for the developed and conventional CFRP.

Some conclusions could be obtained as follows.

(1) Initial damage load and peak load under drop-weight impact of the plainwoven CFRP using spread tow were higher than those of conventional one.

(2) The developed CFRP reinforced by spread tow has advantage in its structure that absorbs large amount of energy after damaged in the initial stages.

(3) The developed CFRP maintained superior mechanical properties close to original them, even after the material was damaged due to impact, because critical propagation of the damage was prevented around the warp of thin cloth.

\section{Acknowledgement}

The authors would like to thank Industrial Technology Center of Fukui for providing plain-woven CFRP reinforced by spread tow. 


\section{References}

[1] A. P. Mouritz, M. K. Bannister, P. J. Falzon, K. H. Leong, Composites: Part A 30 (1999), 1445-1461.

[2] M. Todo, K. Takahashi, P. Beguelin, H. H. Kausch, Composite Science Technology, 60 (2000), 763-771.

[3] T. Fujii, S. Amijima, K. Okubo, Composite Science Technology, 49 (1993), 327-333.

[4] K. Kawabe, T. Matuo, Z. Maekawa, J. Society Materials Science, Japan (in Japanese), 47-7 (1998), 727-734.

[5] T. Gomez-del Rio, R. Zaera, E. Barbero, C. Navarro, Composites: Part B 36 (2005), 41-50.

[6] Daniel Delfosse, Anoush Poursartip, Composites: Part A 28A (1997), 647-655.

[7] M.V. Hosur, U.K. Vaidya, C. Ulven, S. Jeelani, Composites Structures 64 (2004), 455-466.

[8] M.V. Hosur, M. Adbullah, S. Jeelani, Composites Structures 67 (2005), 253-262.

[9] Charles Breen, Felicity Guild, Martyn Pavier, Composites: Part A 36 (2005), 205-211.

[10] Surya D. Pandita, Didier Falconet, Ignaas Verpoest, Composites Science and Technology 62 (2002), 1113-1123.

[11] S. A. Hitchen, R. M. J. Kemp, Composites 26 (1995), 207-214. 